\title{
XII.-Action of Bromanile on Secondary and Tertiary Monamines.
}

By James H. Sterbins, JR., S.B.

A few months ago, my attention was attracted by an article in the Ber. d. d. chem. Gesell., 12, 1610, entitled "On Some New Dyes."

Since then, several other publications on the same subject have made their appearance, and can be found in Die Chem. Industrie, and Dingler's Polytechn. Journal.

The articles all describe purple, blue and green dyes, produced by the action of chloranile, on secondary, tertiary and benzylated monamines. This color-bearing reaction, may, therefore, be divided into three steps, viz.: 1st. 'The action of chloranile on tertiary amines. 2d. Its action on secondary monamines. 3d. Its action on benzylated monamines. The first yielding fine blue dyes, the second, violet, and the third, green dyes.

If one molecule of chloranile is allowed to react on two mols. of dimethylaniline, $\mathrm{C}_{6} \mathrm{H}_{5} \mathrm{~N}\left(\mathrm{CH}_{3}\right)_{2}$, at the ordinary temperature of the air, a fine blue color is instantly perceived throughout the mixture; but if gently heated over the steam bath, the mass thickens and the color deepens, till, finally, a drop of the substance, withdrawn from the nixture, becomes hard and brittle on cooling, and assumes a fine bronze lustre.

At this point the reaction is ended, and the mass, after cooling, is broken up, introduced into a flask, and the excess of dimethylaniline is driven off by steam. The remaining substance is then dissolved in strong alcohol and thrown into cold water, which precipitates the coloring matter in the form of dark blue flakes. The precipitate thus formed is gathered on a filter, washed and dried.

It is insoluble in water, but easily soluble in alcohol and ether, and glacial acetic acid.

If treated with sulphuric acid, a sulpho acid is formed, which is likewise a fine blue dye, and easily solubie in water.

Methylaniline and chloranile, under the same circumstances as above, yield a violet dye, which is likewise insoluble in water, and yields a soluble sulpho acid.

Being struck with the beauty of these compounds, and the ease with which they are produced, I was naturally led to consider whether bromanile $\left(\mathrm{C}_{6} \mathrm{Br}_{4} \mathrm{O}_{2}\right)$ would, under the same circumstances, 
produce similar results; and, with this view, the following experiments were made:

My first object was to find a method which would yield considerable quantities of bromanile, in the least amount of time. The following method was finally adopted:

1 part of phenol is added, little by little, to 10 parts of bromine and $3 \frac{1}{2}$ parts of iodine (under water), and heated to $100^{\circ} \mathrm{C}$. for 1 to 2 hours. The raw material, thus formed, is collected on a filter, washed with water, and then heater with $\left(\mathrm{CH}_{\mathrm{y}}\right.$. This dissolves out all impurities, and leaves the pure bromanile behind, in the shape of golden yellow leaflets.

This body being now produced, I was anxious to see whether it would produce a blue dye with methyldiphenylamine, and I proceeded as follows:

If one molecule of bromanile and two molecules of methyldiphenylamine are allowed to react on one another, at the ordinary temperature, the result, as in the case of chloranile, is a blue coloration throughout the mass ; if heated on the steam bath, the mixture thickens, and assumes a fine bronze lustre, and, finally, becomes hard and brittle on cooling.

The mass is then broken up, placed in a flask, and the excess of methyldiphenylamine driven off by steam. It is then dissolved in 95 per cent. alcohol, and thrown in cold water, which precipitates the coloring matter in the form of deep blue flakes, with a bronze lustre.

This is insoluble in water, but easily soluble in alcohol, to which it imparts a beautiful blue color.

It dissolves readily in strong $\mathrm{H}_{2} \mathrm{SO}_{4}$, to form a sulpho acid. This latter is quite soluble in water and alcohol, and is a strong blue dye.

A compound similar to this is produced, if equal molecules of methylaniline and bromanile are allowed to react on one another.

The mixture is heated on the steam bath till it thickens, and is then poured (while still hot) on a piece of cold marble or glass.

On cooling, it can easily be broken up, and is then treated with a current of steam, or heated with dilute $\mathrm{HCl}$, to remove the excess of methylaniline. It is then washed, dissolved in alcohol, and precipitated by cold water, in the shape of violet-blue flakes, with the same bronze lustre as the previous compound.

It is likewise insoluble in water, and easily soluble in alcohol, with a fine violet-blue color.

It is easily dissolved by strong $\mathrm{H}_{2} \mathrm{SO}_{4}$, but is partially re-precipitated by cold water. If, however, it is dissolved in fuming $\mathrm{H}_{2} \mathrm{SO}_{4}$, 
heated for some time on the steam bath, and then poured into cold water, a clear blue liquid is obtained.

This liquid is neutralized with $\mathrm{CaCO}_{3}$, and the $\mathrm{CaSO}_{4}$ filtered off. The lime salt is then decomposed with $\mathrm{Na}_{2} \mathrm{CO}_{3}$, and the soda salt obtained, is evaporated to dryness. It is very soluble in water, and dyes silk and wool a fine violet-blue color.

It may, therefore, be seen from this that bromanile behaves in nearly the same way as its related compound, chloranile, on secondary monamines, and the difference of color was probably due to the impurity of my methylaniline, as the latter is very hard to obtain free from dimethylaniline.

However, the result on tertiary amines is very satisfactory, as it proves that nearly the same tints of colors are produced in both cases.

The dyes herein described are only few in comparison with what might be obtained ; for, it will naturally be understood, that by substituting the methyltoluidines, xylidines and naphthylamines, for methylaniline, and, on the other hand, substituting the dimethyltoluidines, xylidines and naphthylamines, for dimethylaniline, etc., or using the benzylated amines, a large number of violet, blue and green dyes are here possible.

The nature of these bodies I have not yet had time to determine, but hope to do so ere long.

NEW York, Feb. 25th, 1880.

XIII.-ON the Detection of Starch Sugar Mechanicalit Mixed with Refuned Cane Sugar.

By P. Casamajor.

About a year ago we were often entertained by the daily press with accounts of the adulterations practiced by sugar refiners, and, among these adulterations, the one most generally used, as we were then told, was the mixing of refined sugar with starch glucose. I must confess that I never believed in such a practice; for, although I had tried to procure specimens of such sugars, I was not able to find any, and one or two specimens which were given to me, as of sugar so adulterated, turned out to be pure, so far as the presence of starch sugar was concerned. The idea that these sugars were so adulterated, very likely originated in the imperfection of the processes used to detect the presence of starch sugar. 